\title{
Multidisciplinary centres for safety and quality improvement: learning from climate change science
}

\author{
Charles Vincent, ${ }^{1}$ Paul Batalden, ${ }^{2}$ Frank Davidoff ${ }^{3}$
}

\begin{abstract}
${ }^{1}$ Imperial Centre for Patient Safety \& Service Quality, Imperial College London, London, UK

${ }^{2}$ The Dartmouth Institute for Health Policy \& Clinical Practice, Dartmouth Medical School, Hanover, New Hampshire, USA ${ }^{3}$ Institute for Healthcare Improvement, Boston, Massachusetts, USA
\end{abstract}

Correspondence to Professor Charles Vincent, Department Biosurgery \& Surgical Technology, 10th Floor QEQM Building, Imperial College London, St Mary's Campus, Praed Street, London W2 1NY, UK; c.vincent@imperial.ac.uk

Accepted 16 November 2010

\section{ABSTRACT}

Effective improvement and research rely on sustained multidisciplinary collaboration, but few examples are available of centres with the broad range of disciplines and practical experience that are needed to sustain long-term improvement in healthcare quality and safety. In a number of respects, the parlous state of the quality and safety of medical care resembles the problem of climate change. Both constitute a profoundly serious man-made threat to the public good which have until recently been both ignored and denied but are increasingly being recognised, taken seriously and acted on. Among the most interesting and important responses to the challenge of climate change has been the creation of Centres of Climate Change in which experts from multiple diverse disciplines are brought together to tackle the problem. Such centres, while science-based, express their vision in solid pragmatic terms and embrace policy, public engagement and education as essential components of that vision. Cross-discipline collaboration has unfortunately not achieved the same effectiveness or visibility in healthcare quality and safety as it has in the area of climate change. The authors argue that there is a need to create multidisciplinary centres in healthcare to accelerate the improvement of safety and quality, and provide the necessary theoretical and empirical foundations. Such centres would draw on disciplines such as epidemiology, statistics and relevant clinical disciplines but equally from psychology, engineering, ergonomics, sociology, economics, organisational development in addition to engaging with patients and citizens and leaders with practical experience of improvement in the field. In this paper, we address some of the pragmatic challenges of creating such centres and consider how the right groups and networks of researchers and practitioners might be assembled.

\section{INTRODUCTION}

This paper is freely available online under the BMJ Journals unlocked scheme, see http://qualitysafety.bmj. $\mathrm{com} / \mathrm{site} / \mathrm{about} / \mathrm{unlocked}$. xhtml
Improving the safety and quality of healthcare has proved to be an extremely challenging problem clinically, technically, psychologically and in cultural terms. Healthcare is the largest industry in the world, and its problems are deeply embedded within the care delivery systems, the systems of health professional formation and development, and the inertia and resistance to change inherent in huge complex systems. Despite these daunting prospects, optimism is growing that, with a concentrated effort of the right kind, the safety and quality of care that patients receive can be improved in meaningful ways. At the same time, moreover, patients are increasingly demanding that healthcare aim for the same standards of safety and reliability that are achieved in other industries. ${ }^{1}$

Although many clinicians and researchers have suggested that multidisciplinary work can improve processes and outcomes substantially in clinical care,${ }^{2-4}$ few examples are available of centres with the broad range of disciplines and practical experience in research and implementation that are needed to sustain long-term improvement in healthcare quality and safety. In this paper, we address some of the pragmatic challenges of bringing disciplines together, and consider how the right groups and networks of researchers and practitioners might be assembled. First, however, we briefly set out the arguments for multidisciplinary work in this area and consider which disciplines should be represented.

\section{CLIMATE SCIENCE AS AN EXEMPLAR FOR SAFETY AND QUALITY}

In a number of respects, the parlous state of the quality and safety of medical care resembles the problem of climate change. Both constitute a profoundly serious and growing man-made threat to the public good that has until recently been both ignored and denied ${ }^{5}$ 
(table 1) but is increasingly being recognised, taken seriously and acted on ${ }^{6-8}$ Among the most interesting and important responses to the challenge of climate change has been the creation of Centres of Climate Change in which experts from multiple diverse disciplines are brought together to deal with the problem. We can see by examining the websites of some climate changes centres (box 1) that they have been deliberately and carefully structured to combine the relevant range of disciplines in long-term collaboration. Furthermore, they express their vision in solid pragmatic terms and embrace policy, public engagement and education as an essential component of that vision. Cross-discipline collaboration has unfortunately not achieved the same effectiveness or visibility in healthcare quality and safety as it has in the area of climate change. We submit that understanding the forces that have resulted in the efflorescence of crossdisciplinary collaboration in climate change, the ways in which that collaboration operates, as well as its results, strengths and limitations can provide important lessons for the future development of healthcare improvement.

\section{MULTIDISCIPLINARY NATURE OF HEALTHCARE QUALITY AND SAFETY}

As is true for other highly complex, urgent socio-technical problems, patient safety and healthcare quality improvement are meeting points for a multitude of other disciplines. Quality improvement has traditionally drawn on disciplines that emerged from the manufacturing industry and have been transferred to the healthcare environment. Modern approaches to quality improvement have recognised the quantum improvements made to service delivery, processes and cost in other industries, and have sought to apply these to healthcare. ${ }^{9}$ Measurement, statistical process control and an understanding of the nature, pace and requirements of organisational change are all fundamental to any enduring improvement.

Efforts to increase patient safety have enriched but also complicated the basic improvement model by addressing topics such as error and cognition, and have brought a deeper understanding of the importance of context and multilevel systems in the delivery of care. The relevant published literature is difficult for any one person or group to grasp, being scattered, diverse and multidisciplinary in nature. Much of it is published in areas such as cognitive psychology and ergonomics that are unfamiliar to medicine. Furthermore, many of the topics fundamental to progress in patient safety are themselves the subjects of huge literatures and much debate. For instance, a substantial amount of work has been carried out, from a number of different perspectives, on the factors that produce safe, high-performing teams. The same could be said of expertise generally, as well as decision-making, human error, human factors, information technology, leadership, organisational culture and other topics. ${ }^{10}$

Table 1 Challenges and response to climate change and healthcare improvement

\begin{tabular}{|c|c|}
\hline Climate change & Healthcare quality and safety \\
\hline Challenges & Challenges \\
\hline An ecosystem and societal threat & A societal threat \\
\hline $\begin{array}{l}\text { Relatively newly perceived problem driving the interest, } \\
\text { concern, opportunities }\end{array}$ & $\begin{array}{l}\text { Beginning to be framed as a coherent problem, } \\
\text { capable of being meaningfully measured }\end{array}$ \\
\hline Sustained, long-term change required & Sustained long-term change required \\
\hline $\begin{array}{l}\text { Established institutes now addressing the multifaceted } \\
\text { nature of the problem }\end{array}$ & $\begin{array}{l}\text { Small centres emerging but few in number } \\
\text { and precarious support }\end{array}$ \\
\hline Need for multidisciplinary approaches accepted & Multidisciplinary work sporadic \\
\hline Disciplines need to work together in a common space & Necessary but rarely achieved \\
\hline Response & Response \\
\hline The challenge has attracted new sources of funding & Funding streams still precarious \\
\hline New language and concepts emerging & Same principle but not yet established \\
\hline Major multidisciplinary centres established & $\begin{array}{l}\text { Smaller centres established but few with long-term } \\
\text { security }\end{array}$ \\
\hline $\begin{array}{l}\text { Attracts systems thinkers who enjoy crossing } \\
\text { disciplinary boundaries }\end{array}$ & Same, but not well developed \\
\hline Established experts & Leaders emerging \\
\hline $\begin{array}{l}\text { People who come together maintain a 'foot' in their } \\
\text { home departments }\end{array}$ & Yet to be firmly established \\
\hline $\begin{array}{l}\text { Strong public engagement and pressure for individual } \\
\text { behaviour changes }\end{array}$ & $\begin{array}{l}\text { Public engagement mainly restricted to } \\
\text { activists and pioneers. Potential for patient and } \\
\text { public involvement still nascent. }\end{array}$ \\
\hline $\begin{array}{l}\text { Considerable debate on the extent and impact of } \\
\text { climate change }\end{array}$ & Similar debate about extent of problems \\
\hline
\end{tabular}


Box 1 Multidisciplinary centres for study and action on climate change

Tyndall centre

- We bring together scientists, economists, engineers and social scientists who are working to develop sustainable responses to climate change. We work not just within the research community, but also with business leaders, policy advisors, the media and the public in general.

- The centre's vision is to become an internationally recognised source of high-quality and integrated climate-change research, and to exert a seminal influence on the design and achievability of the long-term strategic objectives of UK and international climate policy.

- The purpose of the centre is to research, assess and communicate from a distinct transdisciplinary perspective, the options to mitigate, and the necessities to adapt to, climate change, and to integrate these into the global, UK and local contexts of sustainable development.

http://www.tyndall.ac.uk

The Grantham Institute at Imperial College London

- We recognise that success requires new approaches to collaboration across traditional research disciplines. Therefore, we are funding new academic appointments and studentships, and creating strategic networks within climate-related research areas across the College and beyond.

- It is vitally important that decision-makers and the public understand the evidence behind the headlines. We help achieve this by producing regular briefing papers on our work, translating the research and its implications into publications that will shape global decision-making and impact on policy in the public and private sectors. Through lectures, events and conferences, we are bringing our work to a wider audience including government, industry and non-governmental organisations.

- Drawing on high-quality expertise across areas such as earth sciences, ecology, engineering, medicine, physics and economics, we focus on critical issues such as:

- How do we improve our ability to predict the pace and scale of climate change?

- How will climate change impact on humans and ecosystems?

- What can we do to mitigate the effects of climate change?

- What should we be doing to adapt to climate change?

http://www.imperial.ac.uk/climatechange

The issue of the engagement of the necessary range of disciplines has been thoughtfully addressed by Robert Wears and Shawma Perry, both academic emergency physicians, and Kathleen Sutcliffe, a social scientist, in their discussion of the medicalisation of patient safety. ${ }^{4}$ They point out, following Jens Rasmussen, that 'requisite variety' is critical to complex multidisciplinary problems such as safety. ${ }^{11}$ Requisite variety means that a research team has 'a sufficiently diverse set of backgrounds, viewpoints, skills, and interests, such that hidden assumptions are exposed, a broader repertoire of options, tactics, and tools made available, tacit knowledge made more explicit, and more interpretations and preferences expressed. If a team enlarges what it can do, it also enlarges what it can see.'

\section{SOME BENEFITS OF MULTIDISCIPLINARY WORK IN HEALTHCARE IMPROVEMENT SO FAR}

Several important examples of multidisciplinary work already exist in the areas of safety and quality research and improvement. For instance, in the last 5 years, a number of multidisciplinary groups have made important progress in the understanding, definition and development of non-technical skills in anaesthetics and surgery ${ }^{12}$ and in surgical teamwork. ${ }^{13-16}$ These groups have developed, and prospered, through the personal relationships of those involved and through their ability to raise research funds to maintain momentum and progress. Effective collaborations exist, but the majority rely on always precarious short-term funding. These groups have primarily drawn on scientific work on teams, decisionmaking and skills but also on the practical techniques of communication, briefing, checklisting and debriefing, developed in the military and commercial aviation.

At an institutional level, we can point to The Dartmouth Institute for Health Policy and Clinical Practice, which has built collaboration between the business school, the medical school and clinicians in a wide range of settings. The fruits of this collaboration include the business inspired clinical microsystem concept and its application in a host of quality-improvement programmes. Organisations such as the Institute for Healthcare Improvement and Qulturum in Jönköping County Council in Sweden have also constantly sought out ideas, concepts and practices from other disciplines and industries, though not necessarily in the form of permanent collaborations.

\section{BARRIERS TO MULTIDISCIPLINARY DISCIPLINARY WORK}

Wears, Perry and Sutcliffe ${ }^{4}$ provide a graphic illustration from the USA of a serious risk to the development and maintenance of interdisciplinary work, specifically, the fading of the initial appreciation of the contribution of other disciplines to patient safety. In their discussion of the 'medicalisation of patient safety' they argue, on the 
basis of a review of speakers at prominent patient safety conferences over the years, that:

\begin{abstract}
Although we do not believe that anyone involved in patient safety or patient safety research openly disputes the idea that there is much to be learnt by applying the 'safety sciences' to the problems of healthcare, we wish to point out a disquieting trend. Experts in the safety sciences have been gradually disappearing from view in patient safety. At the first Annenberg meeting in 1996, almost 20\% of the speakers were scientists and scholars from nonhealthcare fields, such as psychology, engineering, sociology, organisational behaviour, etc. An additional 20\% were also not directly associated with healthcare but represented other important viewpoints, such as the law, or patients and their families.... the absolute number and the relative proportion of safety scientists speaking at these meetings have fallen sharply. (p 6)
\end{abstract}

Effective, innovative multidisciplinary work on safety and quality has emerged and prospered in many settings. Over the field as a whole, however, the initial enthusiasm has not been sustained. This suggests to us that although multidisciplinary work is valued, it is very hard to achieve and sustain in practice. What are the principal barriers to multidisciplinary work on quality and safety?

\section{Social identity and communities of practice}

In this issue of BMJ Quality EO Safety, Jean Bartunek ${ }^{17}$ describes the pervasive influence and effects of social identity in determining the professional behaviour and attitudes of others who do not share that identity. At its most extreme, this manifests as the crude tribalism sometimes seen in clinical environments. Bartunek points to the importance of a superordinate objective in uniting people from different disciplines and backgrounds.

\section{An inward looking culture in healthcare}

Healthcare is an all-consuming profession that tends to be distrustful of outside, less well-known influences. This phenomenon has been described by Roger Kneebone as 'total internal reflection." ${ }^{18}$ Wears et al suggest that 'Doctors and nurses are smart, ambitious, hardworking people who have been socialised to feel as though they should be able to resolve any problem they encounter with little outside assistance. And when they do seek assistance, it is almost always from other health professionals; we never look outside our own silo, ${ }^{4}$ (p 5).

\section{Not scientific and not invented here}

The concepts and methods that are common in the social sciences, particularly those from a more interpretative tradition, are quite different from the scientific methods and procedures common in healthcare. Healthcare professionals may regard the methods of social sciences as at best unfamiliar and at worst unscientific, not recognising that disciplines such as psychology embrace both rigorous experimental methodologies and qualitative approaches.

\section{Attitudes and experience of other disciplines}

While social scientists, for instance, can work effectively with clinicians without a detailed understanding of the clinical environment, they do need to be sensitive to their impact on clinical settings, and try to appreciate the pressures, dilemmas and values of the clinical disciplines. Some social scientists have written about clinical work with great insight and sensitivity ${ }^{19-21}$ (there are also, regrettably, examples of studies by social scientists that are both patronising and arrogant). Bosk writes memorably of the delicate balancing act between empathising with those you are studying and maintaining sufficient critical distance to provide a persuasive account of the clinical milieu ${ }^{19}$ (p 12).

\section{Conservative approaches of funding bodies}

Some funding agencies, such as the Agency for Health Research and Quality took on a considerable challenge and also some risk in funding patient safety research; in doing so it gave legitimacy to the field and brought intelligence and energy to bear on the problem. However, even those agencies which did fund research on patient safety have tended to 'play safe' in concentrating for the most part on familiar forms of health services research and not reaching out to other disciplines. The problem of safety was conceived largely in practical terms not requiring extensive investment in understanding the basic mechanisms driving or eroding safety in healthcare organisations. ${ }^{22}$

\section{A place to meet}

A critical barrier for many collaborating groups is simply the lack of a common working environment or at least a meeting place in which conversations can begin and ideas develop. Many of the other barriers of identity, status, mutual incomprehension and ideological divides can potentially break down if people are given enough time together and common space, both intellectual and physical, in which to explore their differences and commit to their common objectives.

\section{Health and healthcare is 'personal'}

An additional barrier that may be intrinsic to healthcare is the deeply personal nature of the way that any disease produces illness and illness burden in a particular individual. This can induce a misguided resistance to the standardisation of core clinical processes that lies at the core of many attempts to improve safety and quality. Some also fear that the personal nature of the 
relationship between patient and clinician, and the personal experience of illness are not susceptible to generalisable science and enquiry. ${ }^{1}$

\section{OVERCOMING THE BARRIERS}

While the barriers are evident and challenging, we suggest that most can be overcome by a combination of accepting the importance of the enterprise, recognising the excitement and value of crossing disciplines, and providing institutional backing for those willing to follow such a path. The greatest challenge is to find both effective and stable ways of supporting such partnerships institutionally, particularly in developing the careers of young clinicians and researchers who want to work long term on safety and quality in healthcare. Some specific actions that could help in this regard are as follows:

- Innovators and early adopters within various disciplines could set the example of broadening memberships, and publishing cross-disciplinary papers.

- Although scientific creativity may be stimulated by crossing disciplinary boundaries, the process by which a discipline advances is not retained in the textbooks which enshrine the discipline and educate the next generation of researchers. 'Textbooks ... begin by truncating the scientist's sense of his discipline's history and then proceed to supply a substitute for what they have eliminated,23 (pp 136-8), thus emphasising disciplinary traditions and boundaries. Writing textbooks that include the thinking from multiple disciplines could be of particular value, since textbooks tend to be more important in defining the nature of thought in science than in other disciplines.

- Foundations, universities and others could explicitly fund protected time to allow people to develop new and cross-disciplinary skills. Healthcare organisations of all kinds could commit to engaging with safety scientists and other disciplines to achieve the 'requisite variety' for safety and quality. ${ }^{24}$

- Creating career paths that promote multidisciplinary work. Foundations and government agencies could fund cross-disciplinary training and fellowships. The aim here might be to create a critical mass, tipping point where cross-discipline work becomes the norm, at least in some areas. Overcoming this might require direct confrontation of promotions committees, university and other organisational governing boards, administrators and leaders.

\section{CREATING CENTRES FOR SAFETY AND QUALITY IMPROVEMENT}

We have argued that permanent multidisciplinary centres need to be established to provide sustained inspiration, research, training and practical support for implementation and innovation. We believe the time has come to develop a network of permanently established centres that can mount a sustained attack on the intractable problems of safety and quality in healthcare. Small units exist within many hospitals and other healthcare organisations, but are often mainly concerned with regulation and compliance. If such units are to flourish, they probably need to be supported by

\section{Box 2 Aims and functions of proposed multidisciplinary centres for healthcare improvement}

Interdisciplinary collaboration and exchange

Such centres would draw on disciplines such as epidemiology, statistics and relevant clinical disciplines but equally from psychology, engineering, ergonomics, sociology, economics, organisational development as well as engaging with patients, citizens and leaders with practical experience of improvement in the field.

\section{Improvement}

Provide advice and support on how to improve the safety and quality of care and evaluate current and future programmes. Help to apply research learning from other industries and the best in global health to solve quality issues.

Evaluation

Provide the capacity to evaluate current and future projects and programmes that seek to improve the safety and quality of patient care.

Education and training

Provide accredited and other programmes of education for research students, practitioners, managers and leaders. Training for Health Boards and those who carry out investigations would be available with the development of more academic courses over time.

\section{Research}

Multidisciplinary research programme conducted at various levels from individual clinician-patient interface; processes of care to organisational issues and across patient engagement, acute, mental health, primary care and community.

Health policy

To provide evidence-based health policy advice. 
larger centres of improvement and research which can ground their work on safety and quality in a public health perspective. What might such centres look like?

We propose here the creation of several, strategically located core centres, with a set of interlinked goals and functions (box 2). In some cases, a single centre might cover a relatively small health economy such as the 300000 people in Jönköping county council. Larger centres might work with a population of several million in a health region (such as the southwest of England or an American state) or a small country such as Scotland or New Zealand. These centres would carry out education, training, research and improvement activities in their own right but also act as the hub of a wider networks and forum for anyone concerned with the safety and quality of healthcare. Needless to say, they need to reach out to patients and citizens as well as to healthcare staff and researchers.

We believe that the core objective should be the practical and pragmatic one of improving the delivery of healthcare for the benefit of patients. However, these activities must be backed by a serious and wide-ranging multidisciplinary research programme to underpin programmes of improvement, technical innovation and organisational change. The research programme should encompass basic research into human performance in complex environments as well as more applied controlled trials and evaluations of interventions.

The lack of sustained funding bedevils quality and safety improvement and hinders the attack on the deeper and more intractable problems which small projects will never address. In large, well-funded healthcare organisations, funding for improvement is one of the first casualties of mergers or financial crisis. Centres will need core funding from a variety of sources, including healthcare, university, industry, research funding and charitable endowments. In time, further funding would be secured from Masters and $\mathrm{PhD}$ programmes, training, and other research and charity funding. Each centre should also have a substantial educational programme, ranging from short courses for both patients and healthcare staff through to universityaffiliated $\mathrm{PhD}$ programmes. Finally, the centres must seek wider influence and actively reach out to supply the evidence base for policy and to advise on healthcare delivery and reform. They will also, as the climate change centres do, reach out to patients and citizens to foster a wider engagement and support for safe, high-quality healthcare as part of the wider quest for living a life that is both healthy and sustainable.

Acknowledgements We are grateful to $\mathrm{R}$ Wears for his comments and reflections on an earlier draft of this paper.

Funding The International Colloquium was funded by the Health Foundation. The Imperial Centre for Patient Safety \& Service Quality is funded by the UK National Institute of Health Research.

Competing interests None.

Provenance and peer review Not commissioned; externally peer reviewed.

\section{REFERENCES}

1. Vincent C. Patient Safety. 2nd edn. Oxford: Wiley Blackwell, 2010.

2. O'Leary DS. CQI-a step beyond QA. Qual Rev Bull 1991;17:4-5.

3. Woods DD, Cook RI. Nine steps to move forward from error. Cogn Technol Work 2002;4:137-44.

4. Wears RL, Perry SJ, Sutcliffe K. The medicalisation of patient safety. J Patient Saf 2005;1:4-6.

5. Millenson M. Demanding Medical Excellence: Doctors and Accountability in the Information Age. Chicago: University of Chicago Press, 2000.

6. Brennan TA. The Institute of Medicine report on medical errors-could it do harm? N Engl J Med 2000;342:1123-5.

7. Institute of Medicine. Crossing the quality chasm. A New Health System for the 21st Century. Washington, DC: National Academy Press, 2001

8. Leape LL, Berwick DM. Five years after To Err Is Human: what have we learned? JAMA 2005;293:2384-90.

9. Nelson EC, Batalden P, Godfrey MM. Quality by Design. A Clinical Microsystems Approach. San Francisco: Jossey Bass, 2007.

10. Kachalia AB, Mello MM, Brennan TA, et al. Beyond negligence: avoidability and medical injury compensation. Soc Sci Med 2008;66:387-402.

11. Rasmussen J. Risk management in a dynamic society: a modelling problem. Saf Sci 1997;27:183-213.

12. Flin R, O'Connor P, Crichton M. Safety at the Sharp End. A Guide to Non-technical Skills. Guildford, UK: Ashgate, 2008.

13. Undre S, Koutantji M, Sevdalis N, et al. Multidisciplinary crisis simulations: the way forward for training surgical teams. World J Surg 2007;31:1843-53.

14. Undre S, Sevdalis N, Healey AN, et al. Teamwork in the operating theatre: cohesion or confusion? J Eval Clin Pract 2006;12:182-9.

15. Lingard L, Espin S, Whyte $\mathrm{S}$, et al. Communication failures in the operating room: an observational classification of recurrent types and effects. Qual Saf Health Care 2004;13:330-4.

16. Lingard L, Regehr G, Orser B, et al. Evaluation of a preoperative checklist and team briefing among surgeons, nurses, and anesthesiologists to reduce failures in communication. Arch Surg 2008;143:12-17.

17. Bartunek J. Intergroup relationships and quality improvement in healthcare. BMJ Qual Saf 2011;20(S1):i62-i66.

18. Kneebone R. Crossing the line: simulation and boundary areas. Simul Healthc 2006;1:160-3.

19. Bosk C. Forgive and Remember. Managing Medical Failure. 2nd edn Chicago: University of Chicago Press, 2003.

20. Paget M. The Unity of Mistakes: A Phenomenological Interpretation of Medical Work. Philadelphia: Temple University Press, 1988.

21. Berg M. Rationalizing Medical Work. Cambridge, MA: MIT Press, 1997.

22. Cook RI. Lessons from the war on cancer: the need for basic research on safety. J Patient Saf 2005;1:7-9.

23. Kuhn TS. The Structure of Scientific Revolutions. 2nd edn. Chicago: University of Chicago Press, 1970.

24. Bate P, Mendel P, Robert G. Organising for Quality. The Improvement Journeys of Leading Hospitals in Europe and the United States. Oxford: Radcliffe Publishing, 2008. 